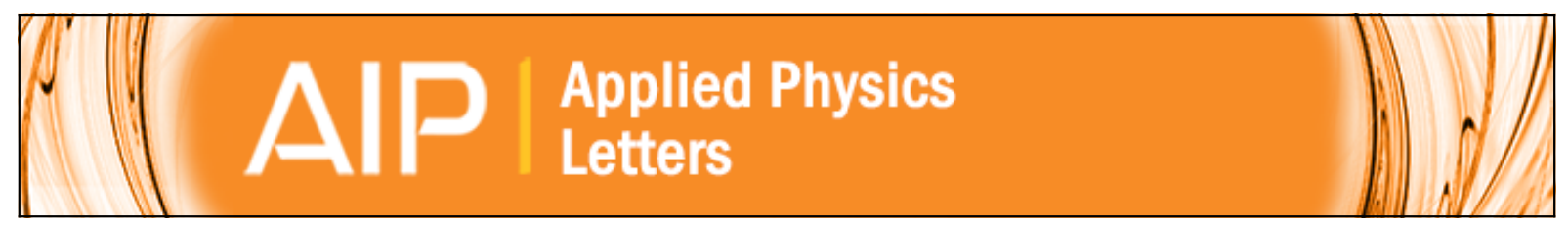

\title{
Separation of vacancy and interstitial depth profiles in ion-implanted silicon: Experimental observation
}

P. Pellegrino, P. Lévêque, J. Wong-Leung, C. Jagadish, and B. G. Svensson

Citation: Applied Physics Letters 78, 3442 (2001); doi: 10.1063/1.1374960

View online: http://dx.doi.org/10.1063/1.1374960

View Table of Contents: http://scitation.aip.org/content/aip/journal/apl/78/22?ver=pdfcov

Published by the AIP Publishing

\section{Articles you may be interested in}

High resolution electrical studies of vacancy-rich and interstitial-rich regions in ion-implanted silicon

J. Appl. Phys. 93, 5118 (2003); 10.1063/1.1564286

Vacancy and interstitial depth profiles in ion-implanted silicon

J. Appl. Phys. 93, 871 (2003); 10.1063/1.1528304

Response to "Comment on 'Separation of vacancy and interstitial depth profiles in ion-implanted silicon:

Experimental observation'” [Appl. Phys. Lett. 80, 1492 (2002)]

Appl. Phys. Lett. 80, 1494 (2002); 10.1063/1.1455141

Comment on "Separation of vacancy and interstitial depth profiles in ion-implanted silicon: Experimental observation" [Appl. Phys. Lett. 78, 3442 (2001)]

Appl. Phys. Lett. 80, 1492 (2002); 10.1063/1.1455140

Depth profiles of vacancy- and interstitial-type defects in MeV implanted Si

J. Appl. Phys. 81, 1639 (1997); 10.1063/1.364019

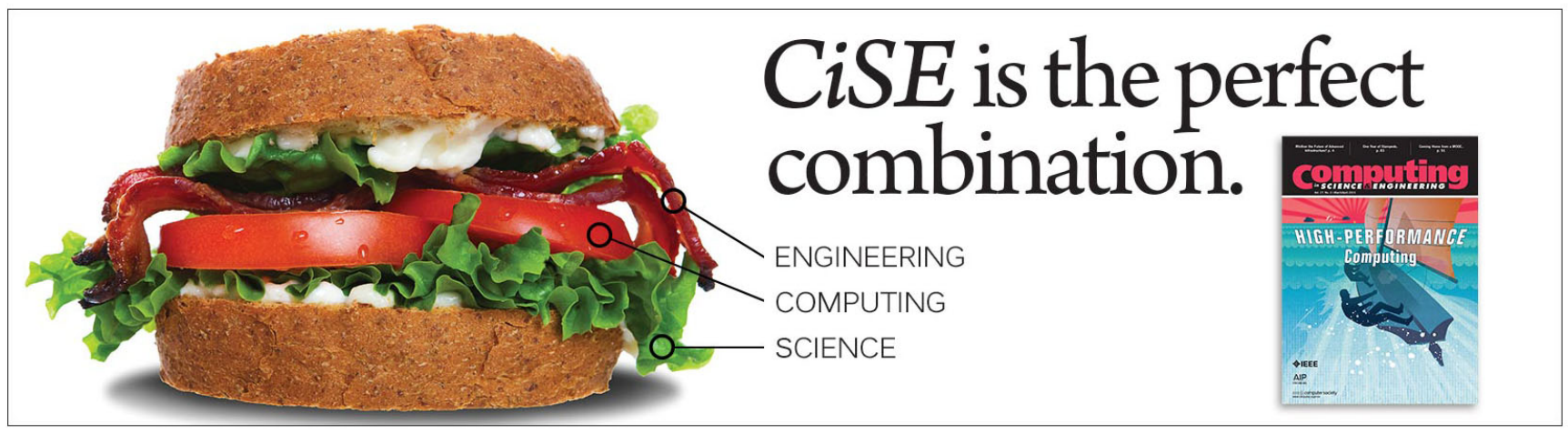




\title{
Separation of vacancy and interstitial depth profiles in ion-implanted silicon: Experimental observation
}

\author{
P. Pellegrino and P. Lévêque \\ Royal Institute of Technology, Solid State Electronics, P.O. Box E229, SE-164 40 Kista-Stockholm, Sweden
}

J. Wong-Leung and C. Jagadish

Australian National University, Department of Electronics Materials Engineering, Research School of Physical Sciences and Engineering, Canberra ACT 0200, Australia

\section{B. G. Svensson ${ }^{\text {a) }}$}

University of Oslo, Physics Department/Physical Electronics, P. B. 1048 Blindern, N-0316 Oslo, Norway and Royal Institute of Technology, Solid State Electronics, P.O. Box E229, SE-164 40 Kista-Stockholm, Sweden

(Received 21 February 2001; accepted for publication 2 April 2001)

\begin{abstract}
An experimental concept of studying shifts between concentration-versus-depth profiles of vacancy and interstitial-type defects in ion-implanted silicon is demonstrated. This concept is based on deep level transient spectroscopy measurements where the filling pulse width is varied. The vacancy profile, represented by the vacancy-oxygen center, and the interstitial profile, represented by the substitutional carbon-interstitial carbon pair, are obtained at the same sample temperature and can be recorded with a high relative depth resolution. For $6 \mathrm{MeV}{ }^{11} \mathrm{~B}$ ions, the peak of the interstitial profile is displaced by $\sim 0.5 \mu \mathrm{m}$ towards larger depths compared to that of the vacancy profile, which is primarily attributed to the preferential forward momentum of recoiling Si atoms. (C) 2001 American Institute of Physics. [DOI: 10.1063/1.1374960]
\end{abstract}

Ion implantation has been used as a doping technique in silicon device processing for more than 30 years $^{1}$ and continues to be a standard "front end" process in the early 21 st century. However, with increasing miniaturization of silicon integrated circuits, the demands on well-controlled dopant distributions (in three dimensions) become extremely severe and ion implantation may not remain the prime doping technique because of the inherent limitations associated with defect generation, postimplant annealing, and dopant diffusion. On the other hand, few viable alternatives exist and consequently, this has stimulated a substantial activity to improve the ability to control implanted dopant distributions. It has been established that anomalous diffusion of $\mathrm{B}$ and $\mathrm{P}$ during postimplant annealing is due to the excess of point defects generated by the implantation. ${ }^{2-7}$ Hence, knowledge of the initial distributions of excess point defects is crucial in order to understand and model the enhanced dopant diffusion.

Because of a preferential momentum transfer from the impinging ions to the silicon atoms in the forward direction, a slight displacement between the vacancy $(V)$ and Si selfinterstitial (I) distributions is predicted. ${ }^{8}$ Although some attempts have been made to observe this shift experimentally by comparing results from spreading resistance measurements on $n$ - and $p$-type samples, ${ }^{9}$ a true comparison between depth profiles of specific vacancy- and interstitial-type defects is still lacking. In this work, we have employed deep level transient spectroscopy (DLTS) to study the shift between the concentration versus depth profiles of the vacancyoxygen center $(\mathrm{VO})$ and the substitutional carbon-interstitial carbon pair $\left(\mathrm{C}_{s} \mathrm{C}_{i}\right)$ in $n$-type samples implanted with $\mathrm{MeV}$

${ }^{a)}$ Electronic mail: b.g.svensson@ @ys.uio.no boron ions. Despite limited to low implantation doses where isolated collision cascades prevail, DLTS is a powerful technique and one of the few where depth profiles of specific defect centers can be obtained. ${ }^{10}$

The samples used were cut from $n$-type (100) oriented float zone (FZ) silicon wafers doped with phosphorus and having a resistivity of $65 \Omega \mathrm{cm}\left(\sim 8 \times 10^{13} \mathrm{P} / \mathrm{cm}^{3}\right)$. According to Fourier transform infrared absorption measurements, the concentrations of interstitial oxygen $\left[\mathrm{O}_{i}\right]$ and substitutional carbon $\left[\mathrm{C}_{s}\right]$ atoms were both $\sim 5 \times 10^{15} \mathrm{~cm}^{-3}$ (brackets denote concentration values). Implantations were performed at room temperature (RT) with $6 \mathrm{MeV}^{11} \mathrm{~B}$ ions using the 1.7 MV NEC Tandem implanter at the Australian National University. The dose was kept low, $1 \times 10^{8} \mathrm{~cm}^{-2}$, and the resulting carrier compensation was below $5 \%$. The average dose rate was $3 \times 10^{7} \mathrm{~cm}^{-2} \mathrm{~s}^{-1}$ and the incident beam, having a spot diameter of $\sim 1 \mathrm{~mm}$, was scanned over an aperture $\left(2 \times 4 \mathrm{~cm}^{2}\right)$ to ensure uniformity (horizontal scan rate $517 \mathrm{~Hz}$, vertical scan rate $64 \mathrm{~Hz}$ ). After implantation, the samples were chemically cleaned using a standard procedure, which included a final dip in diluted hydrofluoric acid. ${ }^{11} \mathrm{Im}-$ mediately after cleaning, the samples were transferred into a vacuum chamber (base pressure $\leqslant 2 \times 10^{-6}$ Torr), where $\mathrm{Au}$ Schottky barrier contacts $(\sim 1000 \AA)$ were prepared at RT $\left(\leqslant 40^{\circ} \mathrm{C}\right)$ by thermal evaporation. The DLTS setup used is a refined version of the system described in Ref. 12.

A DLTS spectrum of an implanted sample is shown in Fig. 1 and three major levels appear at $\sim 0.42, \sim 0.23$, and $\sim 0.17 \mathrm{eV}$ below the conduction band edge $\left(E_{c}\right)$. The two former ones are primarily ascribed to the single and double negative charge state of the divacancy $\left(V_{2}\right)$ center, ${ }^{13-16}$ respectively, where the $E_{c}-0.42 \mathrm{eV}$ level also contains some contribution from the overlapping signal of the vacancy- 


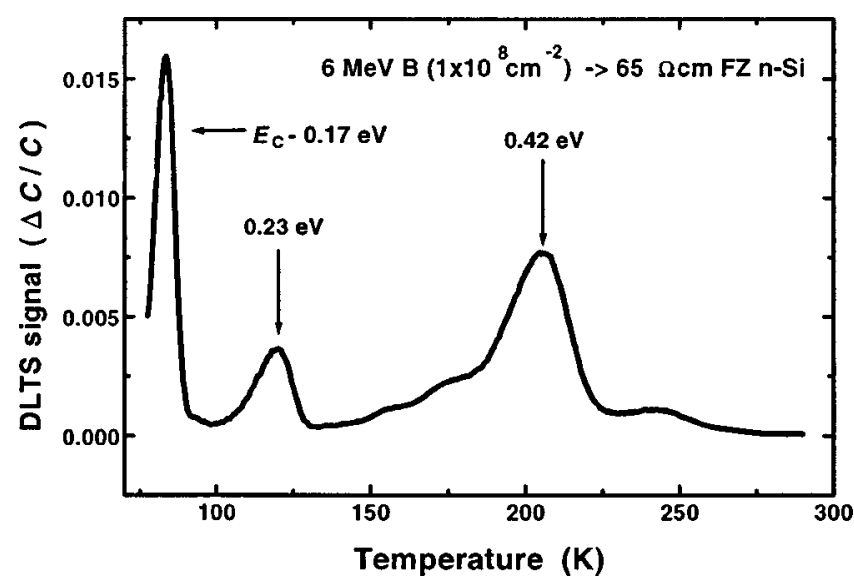

FIG. 1. DLTS spectrum from a $n$-type FZ sample implanted with $6 \mathrm{MeV}$ ${ }^{11} \mathrm{~B}$ ions to a dose of $1 \times 10^{8} \mathrm{~cm}^{-2}$. The rate window is $(100 \mathrm{~ms})^{-1}$, corresponding to an emission rate of $69.3 \mathrm{~s}^{-1}$ at peak maximum, and the width of the filling pulse is $50 \mathrm{~ms}$.

phosphorus (VP) center. ${ }^{15,17}$ In the following, we will focus on the $E_{c}-0.17 \mathrm{eV}$ peak and as demonstrated in Fig. 2, by monitoring its amplitude as a function of the filling pulse duration two contributions are readily resolved. The one with a large capture cross section $\left(\sim 9 \times 10^{-15} \mathrm{~cm}^{2}\right)$ is assigned to the well-known VO center (or the $A$ center). ${ }^{18} \mathrm{VO}$ is formed through the capture of migrating monovacancies by $\mathrm{O}_{i}$ atoms. For $\left[\mathrm{O}_{i}\right] \approx 5 \times 10^{15} \mathrm{~cm}^{-3}$, the average net diffusion length of $V$ before trapping becomes of the order of $0.1 \mu \mathrm{m}$. Because of the low doses used and since $\mathrm{O}_{i}$ is a main impurity with $\left[\mathrm{O}_{i}\right] \gg[\mathrm{VO}]$, the production of $\mathrm{VO}$ reflects the amount of vacancies escaping annihilation. In fact, VO can be considered as a primary defect and as a monitor of the formation of free vacancies. The level with a small apparent capture cross section $\left(\sim 8 \times 10^{-18} \mathrm{~cm}^{2}\right)$ is attributed to the $\mathrm{C}_{s} \mathrm{C}_{i}$ pair ${ }^{19}$ which occurs due to trapping of mobile $\mathrm{C}_{i}$ s by $\mathrm{C}_{s}$ atoms. The $\mathrm{C}_{i} \mathrm{~s}$ are generated by interaction between the implantation-induced $I \mathrm{~s}$ and the $\mathrm{C}_{s}$ atoms and can be regarded as a monitor of the free self-interstitials not recombining with vacancies. Although substantially less mobile than $I$ and $V, \mathrm{C}_{i}$ displays an appreciable mobility at $\mathrm{RT}$ with a diffusion constant of $\sim 1 \times 10^{-15} \mathrm{~cm}^{2} / \mathrm{s}$ at $300 \mathrm{~K} ;{ }^{20}$ for $\left[\mathrm{C}_{s}\right] \approx 5 \times 10^{15} \mathrm{~cm}^{-3}$, the $\mathrm{C}_{s} \mathrm{C}_{i}$ pairs are formed during a time period of a few days after the implantation and the

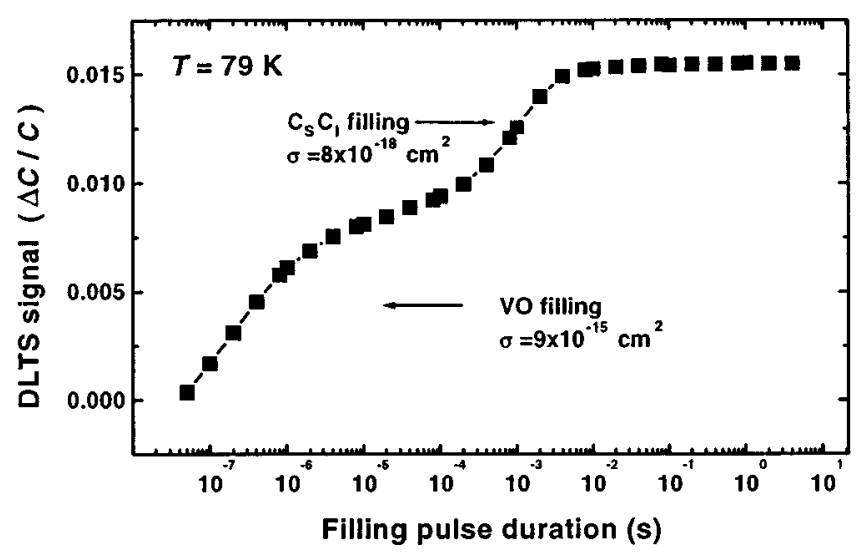

FIG. 2. Amplitude of the $E_{c}-0.17 \mathrm{eV}$ level as a function of the filling pulse duration at a sample temperature of $79 \mathrm{~K}$ The rate window is $(800 \mathrm{~ms})^{-1}$, corresponding to an emission rate of $14.2 \mathrm{~s}^{-1}$ at peak maximum.

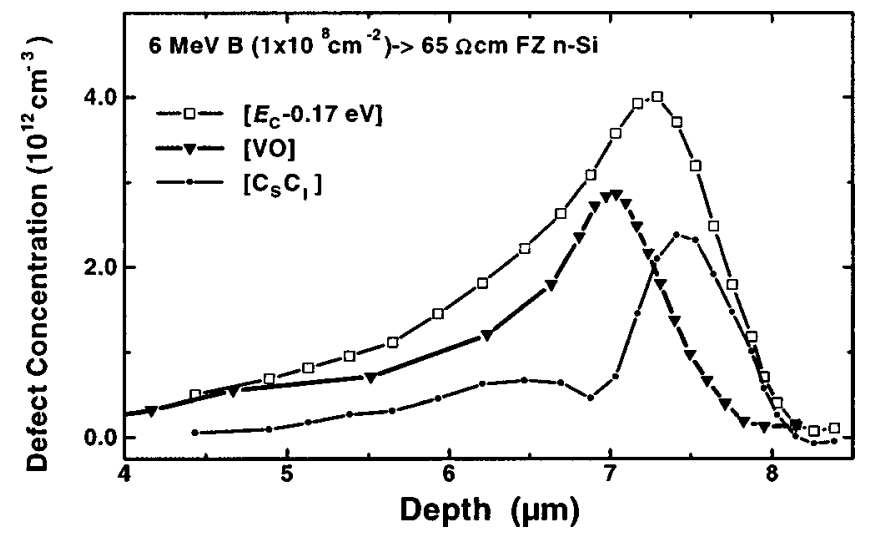

FIG. 3. Concentration vs depth profiles for the total $E_{c}-0.17 \mathrm{eV}$ level, the VO-center and the $\mathrm{C}_{s} \mathrm{C}_{i}$ pair. The $\left[E_{c}-0.17 \mathrm{eV}\right]$ and $[\mathrm{VO}]$ profiles were obtained with a filling pulse width of $50 \mathrm{~ms}$ and $10 \mu \mathrm{s}$, respectively.

effective diffusion length of $\mathrm{C}_{i}$ is on the order of $0.1 \mu \mathrm{m}$. The $\mathrm{C}_{s} \mathrm{C}_{i}$ pair is predominantly observed in oxygen lean samples, where the competing $\mathrm{O}_{i}$ trap for the migrating $\mathrm{C}_{i} \mathrm{~s}$ is suppressed, and it is one of the few well-characterized defects of interstitial type with energy levels in the upper half of the band gap. The $\mathrm{C}_{s} \mathrm{C}_{i}$ pair is thermally stable up to $\sim 200-250^{\circ} \mathrm{C}$ (depending on the purity of the silicon material ${ }^{21}$ but exhibits bistability, i.e., it can exist in two different atomic configurations where the most stable one for the negative charge state gives rise to the $E_{c}-0.17 \mathrm{eV}$ level. ${ }^{19}$

As suggested by the results in Fig. 2, an almost ideal situation occurs for accurate comparison of concentration versus depth profiles between vacancy-type (VO) and interstitial-type $\left(\mathrm{C}_{s} \mathrm{C}_{i}\right)$ defects; only a variation of the filling pulse width is required to distinguish between the two defects. For instance, the sample temperature can be kept constant, excluding any shift in the depth scale caused by variation of the carrier compensation and the Debye length with temperature. Figure 3 compares the profiles of $[\mathrm{VO}]$ and $\left[\mathrm{C}_{s} \mathrm{C}_{i}\right]$ and a substantial shift is resolved with $\left[\mathrm{C}_{s} \mathrm{C}_{i}\right]$ as the deepest one. In the peak region the absolute shift is $\sim 0.5$ $\mu \mathrm{m}$. The VO profile is obtained using a filling pulse width of $10 \mu$ s while the $\mathrm{C}_{s} \mathrm{C}_{i}$ profile is extracted from the difference between the total $E_{c}-0.17 \mathrm{eV}$ profile (filling pulse width 50 $\mathrm{ms}$ ) and the VO profile. The shift is significantly larger than the diffusion lengths involved for $V, I$, and $\mathrm{C}_{i}$ and is predominantly ascribed to the preferential momentum transfer in the forward direction to the recoiling silicon atoms. The $\mathrm{C}_{s} \mathrm{C}_{i}$ profile is almost symmetric around the peak with only a small tail towards the surface and interestingly, the magnitude of the shift revealed in the peak region is close to that deduced by taking the difference between the distributions of silicon recoils and vacancies obtained from transport of ions in matter (TRIM, version 96.01) calculations. ${ }^{22}$ However, the agreement may be fortuitous since this treatment of the TRIM data assumes negligible long distance migration of defects and perfect annihilation of the overlapping $V \mathrm{~s}$ and $I \mathrm{~s}$. As illustrated by the VO profile in Fig. 3, the recombination of $V \mathrm{~s}$ and $I \mathrm{~s}$ is not perfect and competing traps exist for the migrating $V \mathrm{~s}$ and $I$ s. On the other hand, only a few percent of the generated Frenkel pairs survive after implantation at RT and the annihilation process can be considered as quite 
efficient. In order to acquire more systematic data, further work is being pursued to explore a wide range of implant energies and ions.

In conclusion, based on DLTS measurements utilizing the filling pulse technique a new concept of resolving shifts between vacancy $(\mathrm{VO})$ and interstitial $\left(\mathrm{C}_{s} \mathrm{C}_{i}\right)$ depth profiles in ion-implanted silicon is shown. The separation can be studied with a high degree of accuracy since the two profiles are recorded at the same sample temperature. Hence, any shift in the depth scale caused by variation of the carrier compensation and/or the Debye length with temperature can be excluded. In samples implanted with $6 \mathrm{MeV}{ }^{11} \mathrm{~B}$ ions a shift of $\sim 0.5 \mu \mathrm{m}$ is revealed in the peak region, which is predominantly attributed to the preferential forward momentum of recoiling $\mathrm{Si}$ atoms. The magnitude of the shift is consistent with that anticipated from TRIM simulations assuming efficient annihilation of overlapping $V \mathrm{~s}$ and $I s$.

Financial support was kindly provided by the Swedish Research Council for Engineering Sciences (TFR), the Swedish Foundation for International Cooperation in Research and Higher Education (STINT), and the EU Commission, Contract No. ERBFMRXCT980208 (ENDEASDTMR network).

${ }^{1}$ T. Alväger and N. Hansen, Rev. Sci. Instrum. 33, 567 (1962).

${ }^{2}$ P. A. Stolk, H.-J. Gossmann, D. J. Eaglesham, D. C. Jacobson, C. S. Rafferty, G. H. Gilmer, M. Jaraiz, J. M. Poate, H. S. Luftman, and T. E. Haynes, J. Appl. Phys. 81, 6031 (1997), and references therein.

${ }^{3}$ P. M. Fahey, P. B. Griffin, and J. D. Plummer, Rev. Mod. Phys. 61, 289 (1989).
${ }^{4}$ V. Raineri, R. J. Schreutelkamp, F. W. Saris, K. T. F. Jansen, and R. E. Kaim, Appl. Phys. Lett. 58, 922 (1991).

${ }^{5}$ K. Kyllesbech Larsen, V. Privitera, S. Coffa, F. Priolo, C. Spinella, M. Saggio, and S. U. Campisano, Nucl. Instrum. Methods Phys. Res. B 112, 139 (1996).

${ }^{6}$ E. G. Roth, O. W. Holland, V. C. Venezia, and B. Nielsen, J. Electron. Mater. 26, 1349 (1997).

${ }^{7}$ V. C. Venezia, T. E. Haynes, A. Agarwai, L. Pelaz, H.-J. Gossmann, D. C. Jacobson, and D. J. Eaglesham, Appl. Phys. Lett. 74, 1299 (1999).

${ }^{8}$ L. Pelaz, G. H. Gilmer, M. Jaraiz, S. B. Herner, H.-J. Gossmann, D. J. Eaglesham, G. Hobler, C. S. Rafferty, and J. Barbolla, Appl. Phys. Lett. 73, 1421 (1999).

${ }^{9}$ S. Coffa, V. Privitera, F. Priolo, S. Libertino, and G. Mannino, J. Appl. Phys. 81, 1639 (1997).

${ }^{10}$ D. V. Lang, J. Appl. Phys. 45, 3023 (1974).

${ }^{11}$ M. A. Taubenblatt, D. Thomson, and C. R. Helms, Appl. Phys. Lett. 44, 895 (1984).

${ }^{12}$ B. G. Svensson, K. H. Rydén, and B. M. S. Lewerentz, J. Appl. Phys. 66, 1699 (1989)

${ }^{13}$ G. D. Watkins and J. W. Corbett, Phys. Rev. 138, A543 (1965); J. W. Corbett and G. D. Watkins, ibid. 138, A555 (1965).

${ }^{14}$ A. O. Evwaraye and E. Sun, J. Appl. Phys. 47, 3776 (1976).

${ }^{15}$ L. C. Kimerling, IOP Conf. Proc. 31, 221 (1977).

${ }^{16}$ B. G. Svensson and M. Willander, J. Appl. Phys. 62, 2758 (1987).

${ }^{17}$ G. D. Watkins and J. W. Corbett, Phys. Rev. 134, A1359 (1964).

${ }^{18}$ G. D. Watkins and J. W. Corbett, Phys. Rev. 121, 1001 (1961); J. W. Corbett, G. D. Watkins, R. M. Chrenko, and R. S. McDonald, ibid. 121, 1015 (1961).

${ }^{19}$ L. W. Song, X. D. Zhan, B. W. Benson, and G. D. Watkins, Phys. Rev. B 42, 5765 (1990).

${ }^{20}$ A. K. Tripping and R. C. Newman, Semicond. Sci. Technol. 2, 315 (1987).

${ }^{21}$ G. Davies, K. T. Kun, and T. Reade, Phys. Rev. B 44, 12146 (1991).

${ }^{22}$ J. P. Biersack and L. G. Haggmark, Nucl. Instrum. Methods 174, 257 (1980); J. F. Ziegler, J. P. Biersack, and U. Littmark, in The Stopping and Range of Ions in Solids, edited by J. F. Ziegler (Pergamon, New York, 1985), Vol. 1. 